\title{
LCA AS A TOOL FOR ENVIRONMENTAL MANAGEMENT: A LIFE CYCLE INVENTORY CASE STUDY FROM THE GREEK MARKET
}

D. A. GEORGAKELLOS

Received: $14 / 01 / 02$

Accepted: 03/12/02
University of Piraeus,

Dept. of Business Administration

80, Karaoli \& Dimitriou Str. 18534 Piraeus, Greece

to whom all correspondence should be addressed

tel: $+30-210-4142252$

fax: $+30-210-4142339$

e-mail: dgeorg@unipi.gr

\begin{abstract}
Life cycle assessment (LCA) is a technique for holistic environmental assessments of products and processes. The unique feature of this methodology is its focus on the entire life cycle of a product, from raw material extraction to final disposition. In order to assess the role of LCA in environmental management, a comprehensive overview of its theoretical background (including recent aspects of its principles and framework) is presented in this paper. From this overview it is obvious that, in spite of its drawbacks, LCA is recognized as a valuable methodology in environmental management, capable of analysing and assessing in a scientifical way the environmental consequences of various products and activities. Complementary to this analysis, a life cycle inventory (LCI) case study from the Greek market is also presented. In this LCI application, all the methodological issues and guidelines are taken into consideration in order to calculate the resource requirements and the environmental loadings of ten alternative packaging products while some of them are presented by each life cycle stage. The results of this LCI case study cover a long list of inflows and outflows. Notwithstanding that these results are difficult to interpret, they are very detailed and not affected by uncertainties introduced by impact assessment.
\end{abstract}

KEYWORDS: Ecobalance, Impact Assessment, Life Cycle Analysis, Packaging.

\section{INTRODUCTION}

Worldwide interest in life cycle thinking and its significance to public policy and private enterprise has increased rapidly in recent years in concert with more proactive environmental management. The driving force has been the growing global concern over the increasing consumption of finite material resources and degradation of the earth's life support systems. One principal approach and development path of life cycle thinking has been life cycle assessment or LCA, a material and energy mass balance methodology designed to reduce environmental releases and waste. This approach is integrated into life cycle management, a flexible framework of concepts, techniques and procedures addressing environmental, economic and social aspects of products and organizations in order to achieve continuous environmental 
improvement from a life cycle perspective (Henn and Fava, 1994; Hunkeler et al., 2001).

LCA, in general, is a tool to quantify environmental burdens associated with products or activities throughout their life cycle, in other words "from cradle to grave" (Kasai, 1999). The life cycle approach has become widely accepted in both Europe and the United States. Both internal applications for clean product and process development within companies and external application for environmental labelling and information dissemination are common. A full life cycle begins with extraction of raw materials, proceeds through production and use, and ends with waste treatment (Vigon and Jensen, 1995). LCA is often used to compare products with the same function. Another way to use the method is to identify "hot spots", in the life cycle that are critical to the total environmental impact (Andersson et al., 1998). Compared to other environmental assessment tools, LCA is particularly appreciated for its comprehensive life cycle approach. This allows, not only the identification of which phases in the life cycle cause the main environmental impacts, but also to take technical or policy actions to reduce these impacts. Thanks to this, LCA is considered as a very useful and effective instrument for optimisation and improvement of products and processes (Huybrechts et al., 1996). The objective of the present work is to provide a brief but valuable overview of the recent aspects of LCA, together with a case study of a life cycle inventory (LCI) from the Greek market. LCI, which is an accounting of resources consumed, energy input and wastes generated across all the stages of life cycle, is one of the four steps of LCA methodology.

\section{OVERVIEW OF LCA}

LCA is a relatively young technique. It became popular in the early nineties. Initially many thought that LCA would be a very good tool to support environmental claims that could directly be used in marketing. Over the years, it has become clear that this is not the best application of LCA, although it is clearly important to communicate LCA results in a careful and well-balanced way. Today, the most common reasons for the application of LCA are for internal purposes (product improvement, support for strategic choices, benchmarking etc.). In general, two dif- ferent adoption patterns of LCA in companies exist: (a) bottom up: someone in the organisation decides to investigate the usefulness of LCA for his organisation, and (b) top down: top management decides to systematically apply LCA. Both strategies turn to be successful, although in both approaches some major pitfalls can lead to failure in the adoption process. The most important pitfall is the lack of a clear definition of the purpose and application of LCA (Frankl and Rubik, 2000; Goedkoop and Oele, 2001).

\section{Principles and Methodological Framework}

The essence of LCA is the evaluation of the relevant environmental, economic and technological implications of a material, process or product across its life span from creation to waste. The Society of Environmental Toxicology and Chemistry (SETAC) defines the LCA as follows: "The life-cycle assessment is an objective process to evaluate the environmental burdens associated with a product, process or activity by identifying and quantifying energy and raw material usage and environmental releases, to assess the impact of those energy and raw material usage and releases on the environment, and to evaluate and implement opportunities to effect environmental improvements. The assessment includes the entire life cycle of the product, process or activity, encompassing extraction and processing raw materials; manufacturing, transportation and distribution; use, re-use and maintenance; recycling; and final disposal" (Graedel and Allenby, 1995). Four steps are distinguished in the LCA methodology:

1. Goal and Scope Definition,

2. Inventory Analysis,

3. Impact Assessment, and

4. Interpretation.

\section{Goal and Scope Definition}

The goal and scope definition is a guide that helps to ensure the consistency of the LCA study. The goal should state the reason for carrying out the study and to whom it will be communicated. The scope describes the most important methodological choices, assumptions and limitations. Ideally, this phase should lead to definition of certain principles of allocation, system boundaries, system assumptions, functional unit and quality of data. System limitations are made towards nature, geographical area, time frame, capital goods, and 
other product lifecycles, which interact with the process. The functional unit defines the comparison basis. This is a particularly important issue in product comparisons as they may have different performance characteristics. System boundary sets the limit for which elementary processes are included in the study. System assumptions describe how elementary features are handled in calculations. Allocation principles consider output of several products originating from the same production system. Parameters refer to what measurable and descriptive indicators are chosen to describe environmental performance. The quality requirement of data sources depends on the given goal of the study. Data of little influence on the final result need to be less accurate, while dominating sources must be precisely defined (Forsberg, 2000).

\section{Inventory Analysis}

The goal of the inventory is to map out the environmental interventions (a general term for emissions and all other inputs and outputs from and to the environment) per part of the life cycle (Nieuwlaar et al., 1996). In other words, LCI best serves as a means to highlight areas where there might be big opportunities for environmental quality improvements through resource conservation and emissions reductions. The true value of LCI is the realization that a change in one portion of a product's life cycle will have some effect (either positive or negative) in other areas of the product's life cycle. By applying this "life cycle thinking" to the product design process, true improvement opportunities can be identified (Kuta et al., 1995). In the inventory phase, a model is made of the complex technical system concerning production, transportation, use and disposal of a product. This results in a flow sheet or process tree with all the relevant processes. For each process, all the relevant inflows and the outflows are collected. The real hard work in any LCI is the data collection and data treatment itself. There are a number of data sources: data supplied in commercial databases, data supplied by industry sectors, data supplied by universities and other researches, national database projects as they develop in several countries, literature data in general (especially data that describe processes) and specialised internet sites (Goedkoop and Oele, 2001)

\section{Impact Assessment}

Impact assessment characterizes and assesses the effects on the environment of the loadings identified in the previous LCA phase, the inventory analysis. Impact assessment comprises three consecutive elements: (1) classification, (2) characterization, (3) valuation. Classification is the step in which the relevant impact categories, i.e. environmental problem areas, are identified and where the loadings are assigned to each problem area they contribute to. An important step of classification is the selection of the appropriate impact categories. The choice is guided by the goal of the study. This can be illustrated by some examples: resource depletion (depletion of abiotic resources and depletion of biotic resources), pollution (global warming, ozone depletion, human toxicity, ecotoxicity, photochemical oxidant formation, acidification, eutrophication) and degradation of land ecosystems and landscape (land use). Environmental problem types can be ranked on the basis of their geographical scale, from global (climate change) to local (noise, occupational health). Most impact categories relate to regional or global levels and not to the local level. In general, this list can be extended. However, this depends on the type of product system in question (Udo de Haes et al., 1997; Dante et al., 2001).

The characterization element tries to assess the contribution of all input/output data from the inventory to the respective category to finally result in an impact profile for assessed product. This can be achieved by using models, which combine the input/output data from the inventory and a so-called indicator expressing the environmental effects or damages. In general, the indicators allow - in terms of a "unit" - for an aggregation of all emission-based contributions within one category each. If appropriate, characterization factors are used to quantify the contribution of each single emission to that category. The models range from quantitative and internationally accepted ones to experts - or even value-based individual models (Herrchen et al., 1997). The last stage of impact assessment is valuation, which attempts to compare and rank the differing impact categories in order to simplify them down to a common base (Barton et al., 1996). In this element, the different impact categories are weighed against each other. The aim is 
to obtain an overall environmental comparison of the available alternatives. Weighting, normalisation, grouping and ranking are the most common optional steps in impact assessment (Goedkoop and Oele, 2001).

\section{Interpretation}

The last LCA phase concerns interpretation. Here the results of the proceeding LCA phases are compared with the goal of the study set in the goal and scope definition. One crucial element of this phase is validation. In validation, two approaches can be used, which complement each other: (i) performance of sensitivity analysis by the LCA practitioners involved; and (ii) independent, external review (such an external review is often called a peer review). Another element may be the improvement assessment in which options for reducing the environmental impacts of the system under study are identified and evaluated. This is performed on the basis of results from the previous LCA phases. The steps for carrying out the improvement assessment are: (a) load analysis, indicating relevant processes; (b) identification of improvement options; and (c) ranking and selection of the options available based on their effectiveness, and on external variables such as feasibility. Feasibility includes consumer preference and economic aspects and implies a need for data taken outside the scope of life cycle assessment (Udo de Haes et al., 1997).

The LCA phases (and the elements within them), as described above, do not themselves constitute the LCA procedure. The LCA procedure is an iterative process, running through the different LCA phases (and their elements), increasing the level of detail and thus the reliability of the process at each iteration. This might be a selective process. The level of detail is increased in areas, which appear to be key issues for further analysis. This process of selecting key issues is sometimes referred to as screening. SETAC Europe, for example, calls in this context for a three-step approach: (1) screening: identification of elements that can be omitted or where generic data can be used; (2) simplifying: application of the simplifying options identified in the screening step; and (3) assessing reliability: making sure that results are reliable enough to justify the conclusions drawn (Scholl and Nisius, 1998).

\section{CASE STUDY: LCI OF CARBONATED SOFT DRINKS CONTAINERS}

The products that are evaluated and compared in the present life cycle inventory case study are carbonated soft drinks containers (cans and bottles) of the Greek market from glass, plastic (PET) and aluminium in various sizes $(150 \mathrm{ml}, 232 \mathrm{ml}, 250 \mathrm{ml}$, $330 \mathrm{ml}, 500 \mathrm{ml}, 600 \mathrm{ml}, 1500 \mathrm{ml}$ and $2000 \mathrm{ml}$ ). The main purpose of this case study is to calculate and to compare the total environmental effects of these alternative packaging products that serve the same use, throughout their entire life cycle, by taking into consideration the material and the size of them. A secondary purpose of the study is to show how LCA could help in the identification of which phases in the life cycle of a product cause the main environmental impacts. This aim is being achieved by presenting some of the results by life cycle subsystem or stage. As stated above, one of the most important steps of the LCI procedure is the definition of system boundaries. This definition, which is necessary in order to calculate the total environmental consequences, must be as clear as possible. After system boundaries are determined, the system should be divided to subsystems. Each one of these subsystems requires input of materials and energy and has outputs of products (co-products, by-products, intermediate materials etc), atmospheric emissions, waterborne releases, solid waste and other releases. Every broad-based LCA system begins with raw materials acquisition and continues with manufacturing (materials manufacture, product fabrication, packaging etc) use, reuse and maintenance through final disposition (recycling and solid waste management) (Bontoux and Papameletiou, 1998; Georgakellos, 1999).

\section{Definition of the System}

The life cycle system of the present case study consists of eleven subsystems that together cover the entire life cycle of the containers. These subsystems or stages of the system are: (i) raw materials acquisition and materials manufacture, (ii) materials transportation, (iii) containers fabrication, (iv) containers transportation, (v) filling - final product production, (vi) final product transportation, (vii) final product use, (viii) solid wastes collection and transportation for landfilling, (ix) solid wastes landfilling, (x) used containers collection and refilling and (xi) recycling. These eleven stages, that all together form the LCI system, are presented in Figure 1. 


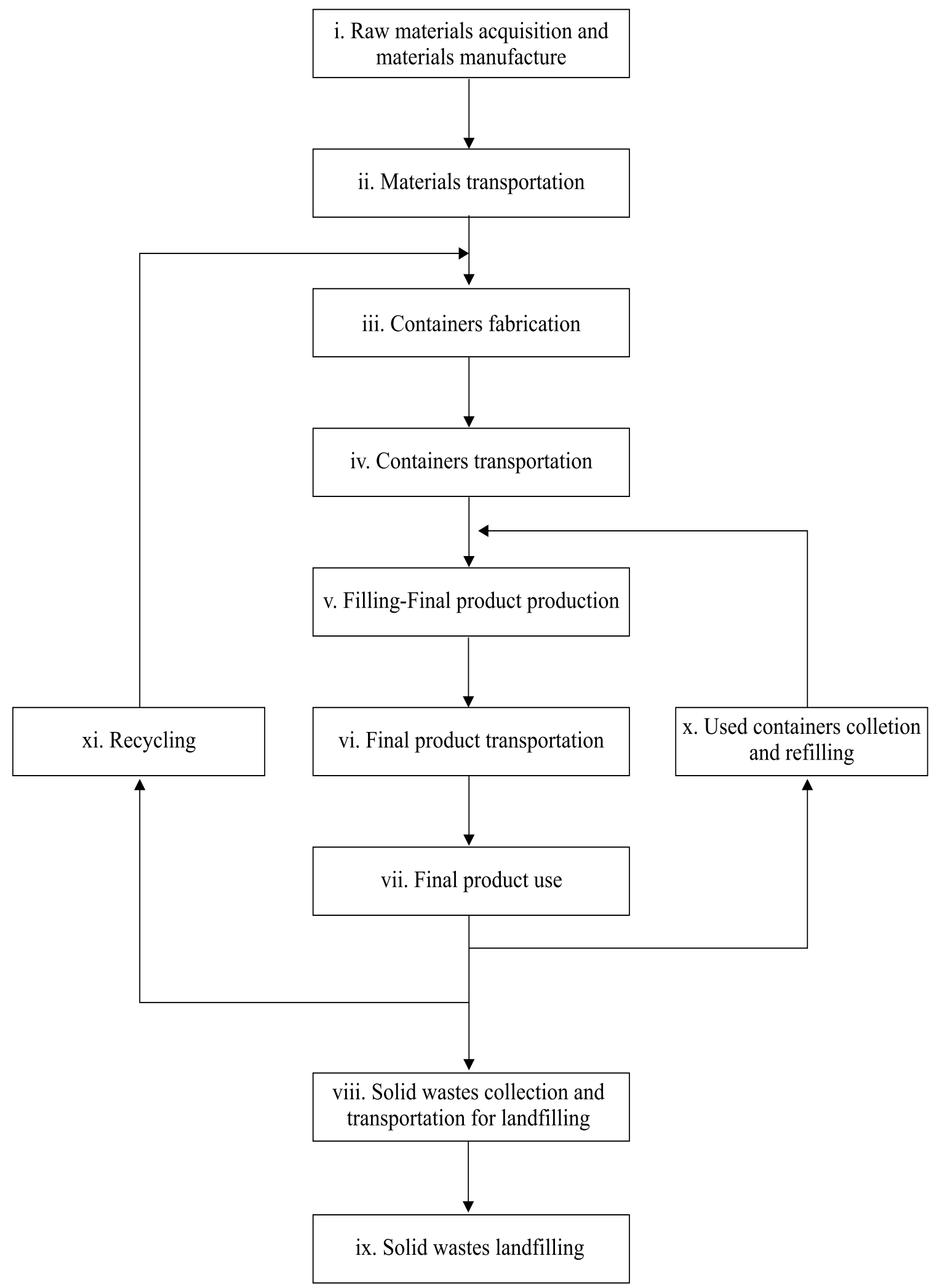

Figure 1. The stages of the system 
The first stage of raw materials acquisition and materials manufacture includes all the activities required to gather or obtain a raw material or energy source from the earth and to process them into a form that can be used to fabricate a particular container (glass, PET and aluminium). The second stage includes transportation of the materials to the point of containers fabrication. In the third stage of containers fabrication, the process step that uses raw or manufactured materials to fabricate a container ready to be filled is included. The next stage encompasses transport of empty containers to the point of filling. All processes that fill the containers and prepare them for shipment are included in filling - final product production stage. However, the filling product (carbonated soft drinks) is not included in the analysis. The transport of filled containers to retail outlets is included in the sixth stage of the system. As in the previous stage, the weight of the filling product (carbonated soft drinks) is not taken into account in the analysis. The seventh stage of final product use comprises activities such as storage of the containers for later use, preparation for use, consumption etc. The solid wastes collection and transportation for landfilling stage begins after the containers have served their intended purpose and enter the environment through the waste management system (landfilling). The next stage includes all necessary activities for the land disposal of waste (sanitary landfills), while the possible consequences of land disposal from subsequent releases to the environment (like methane or any other gas formation and release, groundwater releases and contamination, soil erosion etc) are not included in the analysis. The stage of used containers collection and refilling includes all the activities required to off-site re-use such as the return of the containers to the bottler to be refilled for their original purpose. The eleventh stage (recycling) encompasses all activities necessary to take the used containers out of the waste management system and deliver them to the container fabrication stage. According to the Figure 1, it is obvious that all the three stages for solid waste management (i.e. stages ix, $x$ and $x i$ ) are included in the analysis. This is necessary because it is possible that each one of these three waste management options may be applied (partly or totally) during the life cycle of a container. In this way, it is taken into account the degree of re-use and/or recycling for the examined packaging materials. Therefore, the amount of solid waste calculated in this case study refers to the final waste disposal (landfilling). Obviously, this amount is low when the degree of re-use or the degree of recycling (or both) are high. In the above life cycle system it is possible that some of the subsystems may be merged with other ones. For instance, materials transportation and containers transportation could be merged with raw materials acquisition and manufacture and containers fabrication correspondingly. In this case, transportation activities used to move raw materials and products from one stage to the next have been disaggregated (rather than being presented as a separate stage) which means that each transportation step is associated with the specific upstream life cycle stage. This may happen because, although it is common to present transportation-related energy and emissions separately in reporting results, the transportation system type and the distances covered are defined very often within each stage.

Other special conditions, parameters and assumptions that influence and limit the system are the basis of comparison, the level of technology, the basis of allocation, the capital goods (trucks, injection moulding machines etc) and the energy system. In a comparative life cycle inventory (like the present case study), the basis of comparison should be equivalent usage (Vigon et al., 1993). This means that the system should be defined so that a functionally equal amount of product or equivalent service is delivered to the consumer. Equivalent usage can often be based on volume or weight. Thus, in this LCI, the basis of comparison is 10001 of carbonated soft drinks. The technological level of LCA studies can differ considerably. Several technologies exist for every production process like the best available technology, the optimal technology, the modern technology, the average production technology, the oldest technology still in use etc (Rubik and Baumgartner, 1992). The level of technology of the present study is the mix of the current technology or average technology (technology installed by all producers).

Allocation, in general, involves ascribing a part of all inputs, a part of the environmental outputs and a part of the waste to be processed to one output: the product or the service to be considered in the analysis (Assies, 1992). Many different solutions to the allocation problems have been suggested. The choice of solution can have a decisive impact 
on the results of an LCI. The ISO 14041 standard for LCI requires the following procedure be used for allocation in multifunction processes: (a) allocation should be avoided, wherever possible; (b) where allocation cannot be avoided, the allocation should reflect the physical relationships between the environmental burdens and functions; and (c) where such physical causal relationships alone cannot be used as the basis for allocation, the allocation should reflect other relationships between the environmental burdens and the functions. For allocation in open-loop recycling, the ISO 14041 recommends the same procedure but allows a few additional options (Ekvall and Finnveden, 2001). In this case however, the ISO procedure has been criticised because it does not take into account the fact that different approaches to the allocation problem result in different types of information (Ekvall, 2000). The basis of allocation in the present case study is according to the total weight (per $\mathrm{kg}$ ) of the main products and by-products of the process concerned. Capital goods are often only incorporated as far as their direct functioning is involved. For instance, not the depreciation of the truck that is needed to transport aluminium, but only fuel needs and exhaustion gases are included (Bouman et al., 2000). In this LCI the energy and emissions involved with the production and disposal of capital goods are excluded (except those of trucks and vessels). As for the energy system of the case study, this is based on the national basic energy sources and the national average fuel mix and grid for electricity in Greece.

\section{Results and Discussion}

The next step is the construction of the mathematical model. This model is necessary to calculate the total energy and resource use as well as the total environmental releases from the overall system. This step consists of summing the energy, raw materials and various emission values that result from the energy and material flows, for each stage of the product's life cycle. This model, which defines numerically the relationships of the individual subsystems to each other in the production of the final product, has been developed and analyzed in detail elsewhere (Georgakellos, 1998). The results of the present LCI are presented in Tables 1, 2 and 3. These results are calculated according to the mathematical model and using the collected data. Wherever possible, specific data from the manufacturing industry for production processes, from the energy industry for the electricity and fuels production and distribution, as well as from the municipalities and the trade associations for solid waste management and recycling, are used. Nevertheless, since this is a life cycle inventory for external use, it is extremely difficult to collect data from every plant manufacturing the product or material being analyzed. Furthermore, problems like data gaps (absent or incomplete data), differences in the way data were collected, confidentiality of data and absent of national databases also occurred. Consequently, a number of data sources are used (books, reports, country specific databases, conference papers and articles published in technical journals etc) providing information on processes in the system.

According to the Tables 1-3, no one of the ten containers has the totally best or the totally worst environmental effect. The $250 \mathrm{ml}$ glass bottle has the lowest energy and water consumption; atmospheric emissions of carbon monoxide, hydrocarbons, nitrous oxide, aldehyde, organic compounds, ammonia and hydrogen chloride; waterborne waste of dissolved material, oil, fluoride and ammonia; BOD and solid waste (this container has very high refilling rate), while the 232 $\mathrm{ml}$ glass bottle has the highest atmospheric emissions of lead and volatile organic compounds. The $2000 \mathrm{ml}$ PET bottle has the lowest atmospheric emissions of particles, nitrogen oxides, sulphur dioxide, volatile organic compounds, fluoride and hydrogen fluoride, as well as the lowest waterborne waste of suspended materials and COD. The $330 \mathrm{ml}$ PET bottle has the highest atmospheric emissions of carbon monoxide, nitrous oxide, organic compounds and hydrogen chloride, as well as the highest waterborne waste of dissolved materials, oil, phenol, ammonia, sulphate, nitrate, chloride, Na-ions and Fe-ions. The $150 \mathrm{ml}$ aluminum can has the highest energy and water consumption; atmospheric emissions of particles, hydrocarbons, nitrogen oxides, sulphur dioxide, aldehydes, ammonia and hydrogen fluoride; waterborne waste of suspended materials and fluoride; $\mathrm{BOD}, \mathrm{COD}$ and solid waste. However, the aluminum cans have not at all waterborne waste of phenol (the glass bottles not even), sulphate, nitrate, chloride, $\mathrm{Na}$-ions and $\mathrm{Fe}$-ions, as well as they have no atmospheric emissions of lead (the PET bottles not even). 
Table 1. Inventory Analysis of Carbonated Soft Drinks Glass Bottles of the Greek Market.

\begin{tabular}{|c|c|c|}
\hline \multirow[t]{2}{*}{ Inputs and Outputs } & \multicolumn{2}{|c|}{ Type of Container: Glass Bottles } \\
\hline & $232 \mathrm{ml}$ & $250 \mathrm{ml}$ \\
\hline \multicolumn{3}{|c|}{ Energy Consumption (MJ/1000 l) } \\
\hline Total Fuel plus Feedstock & 13091,91 & 10494,19 \\
\hline \multicolumn{3}{|c|}{ Raw Material Consumption (g/1000 l) } \\
\hline Silica Sand & 18692,6 & 11564,48 \\
\hline Limestone & 7301,797 & 4517,376 \\
\hline Soda Ash & 5841,438 & 3613,901 \\
\hline Bauxite & 0 & 0 \\
\hline Hydrogen & 0 & 0 \\
\hline Oxygen & 0 & 0 \\
\hline Sodium Hydroxide & 0 & 0 \\
\hline Aluminium Fluoride & 0 & 0 \\
\hline Water & 68636,89 & 42463,33 \\
\hline Auxiliary Materials & 5841,438 & 3613,901 \\
\hline \multicolumn{3}{|c|}{ Atmospheric Emissions (g/1000 l) } \\
\hline Particles & 887,034 & 655,4028 \\
\hline Carbon Monoxide & 269,0821 & 192,1243 \\
\hline Hydrocarbons & 85,84743 & 65,73306 \\
\hline Nitrogen Oxides & 3283,648 & 2801,414 \\
\hline Nitrous Oxide & 1,657808 & 1,02563 \\
\hline Sulphur Dioxide & 6831,12 & 5693,381 \\
\hline Aldehydes & 22,46849 & 22,36611 \\
\hline Organic Compounds & 0,362175 & 0,224066 \\
\hline Ammonia & 0,088615 & 0,054823 \\
\hline Hydrogen Chloride & 1,051459 & 0,650502 \\
\hline Fluoride \& Hydrogen Fluoride & 0,408925 & 0,252988 \\
\hline Lead & 0,262865 & 0,162626 \\
\hline Volatile Organic Compounds & 118,7094 & 85,2819 \\
\hline \multicolumn{3}{|c|}{ Waterborne Waste $(\mathrm{g} / 1000 \mathrm{l})$} \\
\hline Suspended Materials & 0,029555 & 0,018285 \\
\hline Dissolved Materials & 52,82183 & 32,67909 \\
\hline BOD & 0,029555 & 0,018285 \\
\hline COD & 0,088615 & 0,054823 \\
\hline Oil & 0,710904 & 0,439812 \\
\hline Phenol & 0 & 0 \\
\hline Fluoride & 0,003476 & 0,00215 \\
\hline Ammonia & 0,00149 & 0,000922 \\
\hline Sulphate & 0,000497 & 0,000307 \\
\hline Nitrate & 0,000993 & 0,000614 \\
\hline Chloride & 0,0000397 & 0,0000246 \\
\hline Na-ions & 0,000497 & 0,000307 \\
\hline Fe-ions & 0,00000497 & 0,00000307 \\
\hline \multicolumn{3}{|c|}{ Solid Waste $\left(\mathrm{cm}^{3} / 1000 \mathrm{l}\right)$} \\
\hline Municipal Waste etc. & 19341,46 & 11965,91 \\
\hline
\end{tabular}


Table 2. Inventory Analysis of Carbonated Soft Drinks Plastic Bottles (PET) of the Greek Market.

\begin{tabular}{|c|c|c|c|c|c|}
\hline \multirow[t]{2}{*}{ Inputs and Outputs } & \multicolumn{5}{|c|}{ Type of Container: Plastic Bottles (PET) } \\
\hline & $330 \mathrm{ml}$ & $500 \mathrm{ml}$ & $600 \mathrm{ml}$ & $1500 \mathrm{ml}$ & $2000 \mathrm{ml}$ \\
\hline \multicolumn{6}{|c|}{ Energy Consumption $(\mathrm{MJ} / 1000 \mathrm{l})$} \\
\hline Total Fuel plus Feedstock & 27336,08 & 20999,05 & 17748,89 & 14346,76 & 13060,76 \\
\hline \multicolumn{6}{|c|}{ Raw Material Consumption (g/1000 l) } \\
\hline Silica Sand & 0 & 0 & 0 & 0 & 0 \\
\hline Limestone & 0 & 0 & 0 & 0 & 0 \\
\hline Soda Ash & 0 & 0 & 0 & 0 & 0 \\
\hline Bauxite & 0 & 0 & 0 & 0 & 0 \\
\hline Hydrogen & 2188,921 & 1537,883 & 1203,976 & 854,4574 & 722,3392 \\
\hline Oxygen & 490495,97 & 34458,53 & 26976,85 & 19145,37 & 16185,07 \\
\hline Sodium Hydroxide & 41,87986 & 29,42379 & 23,03526 & 16,34804 & 13,82027 \\
\hline Aluminium Fluoride & 0 & 0 & 0 & 0 & 0 \\
\hline Water & 138668,9 & 97425,44 & 76272,31 & 54130,16 & 45760,43 \\
\hline Auxiliary Materials & 1873,426 & 1316,224 & 1030,444 & 731,3021 & 618,2265 \\
\hline \multicolumn{6}{|c|}{ Atmospheric Emissions (g/1000 l) } \\
\hline Particles & 418,7884 & 377,3994 & 356,1626 & 333,9391 & 325,5386 \\
\hline Carbon Monoxide & 2184,66 & 1554,898 & 1231,902 & 893,8049 & 766,0042 \\
\hline Hydrocarbons & 3070,171 & 2166,874 & 1703,586 & 1218,638 & 1035,327 \\
\hline Nitrogen Oxides & 2980,271 & 2694,381 & 2547,752 & 2394,268 & 2336,251 \\
\hline Nitrous Oxide & 195,4135 & 137,2929 & 107,4837 & 76,28076 & 64,48605 \\
\hline Sulphur Dioxide & 4928,243 & 4606,816 & 4441,961 & 4269,398 & 4204,17 \\
\hline Aldehydes & 23,08284 & 22,82026 & 22,68559 & 22,54462 & 22,49133 \\
\hline Organic Compounds & 20,46455 & 14,3779 & 11,25615 & 7,988449 & 6,753257 \\
\hline Ammonia & 0,187006 & 0,131386 & 0,102859 & 0,072999 & 0,061712 \\
\hline Hydrogen Chloride & 10,60956 & 7,454027 & 5,835599 & 4,141502 & 3,501134 \\
\hline Fluoride \& Hydrogen Fluoride & 0,001879 & 0,00132 & 0,001033 & 0,000733 & 0,00062 \\
\hline Lead & 0 & 0 & 0 & 0 & 0 \\
\hline Volatile Organic Compounds & 43,81844 & 40,0208 & 38,07305 & 36,03423 & 35,26356 \\
\hline \multicolumn{6}{|c|}{ Waterborne Waste (g/1000 l) } \\
\hline Suspended Materials & 0,037576 & 0,0264 & 0,020668 & 0,014668 & 0,0124 \\
\hline Dissolved Materials & 4963,326 & 3487,114 & 2729,988 & 1937,462 & 1637,887 \\
\hline BOD & 0,037576 & 0,0264 & 0,020668 & 0,014668 & 0,0124 \\
\hline COD & 0,187006 & 0,131386 & 0,102859 & 0,072999 & 0,061712 \\
\hline Oil & 61,33947 & 43,09564 & 33,73867 & 23,9442 & 20,24189 \\
\hline Phenol & 0,093066 & 0,065386 & 0,051189 & 0,036329 & 0,030712 \\
\hline Fluoride & 0,356098 & 0,250186 & 0,195865 & 0,139005 & 0,117512 \\
\hline Ammonia & 0,131516 & 0,0924 & 0,072338 & 0,051338 & 0,0434 \\
\hline Sulphate & 0,056364 & 0,0396 & 0,031002 & 0,022002 & 0,0186 \\
\hline Nitrate & 0,056364 & 0,0396 & 0,031002 & 0,022002 & 0,0186 \\
\hline Chloride & 0,003758 & 0,00264 & 0,002067 & 0,001467 & 0,00124 \\
\hline Na-ions & 0,037576 & 0,0264 & 0,020668 & 0,014668 & 0,0124 \\
\hline Fe-ions & 0,000564 & 0,000396 & 0,00031 & 0,00022 & 0,000186 \\
\hline \multicolumn{6}{|c|}{ Solid Waste $\left(\mathrm{cm}^{3} / 1000 \mathrm{l}\right)$} \\
\hline Municipal Waste etc. & 93959,29 & 66013,55 & 51680,61 & 36677,53 & 31006,36 \\
\hline
\end{tabular}


Table 3. Inventory Analysis of Carbonated Soft Drinks Aluminium Cans of the Greek Market.

\begin{tabular}{|c|c|c|c|}
\hline \multirow[t]{2}{*}{ Inputs and Outputs } & \multicolumn{3}{|c|}{ Type of Container: Aluminium Cans } \\
\hline & $150 \mathrm{ml}$ & $330 \mathrm{ml}(209)$ & $330 \mathrm{ml}(202)$ \\
\hline \multicolumn{4}{|c|}{ Energy Consumption (MJ/1000 l) } \\
\hline Total Fuel plus Feedstock & 60057,91 & 25223,01 & 23923,45 \\
\hline \multicolumn{4}{|c|}{ Raw Material Consumption (g/1000 l) } \\
\hline Silica Sand & 0 & 0 & 0 \\
\hline Limestone & 9853,153 & 3535,374 & 3299,682 \\
\hline Soda Ash & 0 & 0 & 0 \\
\hline Bauxite & 539781,4 & 193677 & 180765,2 \\
\hline Hydrogen & 0 & 0 & 0 \\
\hline Oxygen & 0 & 0 & 0 \\
\hline Sodium Hydroxide & 24165,025 & 8670,565 & 8092,525 \\
\hline Aluminium Fluoride & 2029,253 & 728,109 & 679,5684 \\
\hline Water & 329190 & 118115,5 & 110241,1 \\
\hline Auxiliary Materials & 1093,542 & 392,3699 & 366,2119 \\
\hline \multicolumn{4}{|c|}{ Atmospheric Emissions (g/1000 l) } \\
\hline Particles & 4503,901 & 1795,313 & 1694,266 \\
\hline Carbon Monoxide & 2101,78 & 797,2651 & 748,5988 \\
\hline Hydrocarbons & 4526,055 & 1645,201 & 1537,727 \\
\hline Nitrogen Oxides & 5213,656 & 3165,295 & 3088,879 \\
\hline Nitrous Oxide & 166,6243 & 59,78584 & 55,80012 \\
\hline Sulphur Dioxide & 12439,83 & 6930,51 & 6724,978 \\
\hline Aldehydes & 29,54094 & 24,83398 & 24,65838 \\
\hline Organic Compounds & 11,83731 & 4,247303 & 3,964149 \\
\hline Ammonia & 2,254726 & 0,80901 & 0,755076 \\
\hline Hydrogen Chloride & 5,636815 & 2,022525 & 1,88769 \\
\hline Fluoride \& Hydrogen Fluoride & 56,02994 & 20,1039 & 18,76364 \\
\hline Lead & 0 & 0 & 0 \\
\hline Volatile Organic Compounds & 48,21925 & 37,21043 & 36,79974 \\
\hline \multicolumn{4}{|c|}{ Waterborne Waste (g/1000 l) } \\
\hline Suspended Materials & 0,676418 & 0,242703 & 0,226523 \\
\hline Dissolved Materials & 1791,38 & 642,7584 & 599,9079 \\
\hline BOD & 90,0763 & 32,31995 & 30,16529 \\
\hline COD & 2144,244 & 769,3685 & 718,0773 \\
\hline Oil & 19,50338 & 6,997937 & 6,531407 \\
\hline Phenol & 0 & 0 & 0 \\
\hline Fluoride & 3,382089 & 1,213515 & 1,132614 \\
\hline Ammonia & 0,090189 & 0,03236 & 0,030203 \\
\hline Sulphate & 0 & 0 & 0 \\
\hline Nitrate & 0 & 0 & 0 \\
\hline Chloride & 0 & 0 & 0 \\
\hline Na-ions & 0 & 0 & 0 \\
\hline Fe-ions & 0 & 0 & 0 \\
\hline \multicolumn{4}{|c|}{ Solid Waste $\left(\mathrm{cm}^{3} / 1000 \mathrm{l}\right)$} \\
\hline Municipal Waste etc. & 213251,7 & 76516,07 & 71414,99 \\
\hline
\end{tabular}


Table 4. Inventory Analysis of 0,25 1 Glass Bottle by System Stage (\% of total)

\begin{tabular}{|rrrrrc|}
\hline Stage & Energy & CO & NO $_{\mathbf{x}}$ & COD & Solid Waste \\
\hline I & 1,54 & 0,65 & 1,20 & 98,88 & 2,33 \\
\hline II & 0,09 & 0,08 & 0,10 & 0,00 & 0,00 \\
\hline III & 16,60 & 0,28 & 0,07 & 1,12 & 0,69 \\
\hline IV & 0,33 & 1,98 & 0,16 & 0,00 & 0,00 \\
\hline V & 11,43 & 5,97 & 14,06 & 0,00 & 0,00 \\
\hline VI & 10,25 & 61,56 & 5,10 & 0,00 & 0,00 \\
\hline VII & 48,40 & 29,04 & 58,01 & 0,00 & 0,00 \\
\hline VIII & 0,02 & 0,37 & 0,02 & 0,00 & 0,00 \\
\hline IX & 0,03 & 0,04 & 0,03 & 0,00 & 96,98 \\
\hline X & 11,24 & 0,00 & 21,16 & 0,00 & 0,00 \\
\hline XI & 0,07 & 0,04 & 0,09 & 0,00 & 0,00 \\
\hline
\end{tabular}

Table 5. Inventory Analysis of 0,33 1 Aluminium Can (202 type) by System Stage (\% of total)

\begin{tabular}{|rrrrrc|}
\hline Stage & Energy & CO & NO $_{\mathbf{x}}$ & COD & Solid Waste \\
\hline I & 58,71 & 89,22 & 33,81 & 100,00 & 51,65 \\
\hline II & 0,08 & 0,04 & 0,18 & 0,00 & 0,00 \\
\hline III & 16,74 & 0,00 & 0,00 & 0,00 & 0,00 \\
\hline IV & 0,20 & 0,70 & 0,20 & 0,00 & 0,00 \\
\hline V & 2,72 & 1,53 & 12,75 & 0,00 & 0,00 \\
\hline VI & 0,25 & 0,87 & 0,26 & 0,00 & 0,00 \\
\hline VII & 21,23 & 7,45 & 52,61 & 0,00 & 0,00 \\
\hline VIII & 0,01 & 0,15 & 0,03 & 0,00 & 0,00 \\
\hline IX & 0,02 & 0,01 & 0,05 & 0,00 & 48,35 \\
\hline X & 0,00 & 0,00 & 0,00 & 0,00 & 0,00 \\
\hline XI & 0,04 & 0,01 & 0,11 & 0,00 & 0,00 \\
\hline
\end{tabular}

Table 6. Inventory Analysis of 0,5 1 PET Bottle by System Stage (\% of total)

\begin{tabular}{|rrrrrc|}
\hline Stage & Energy & CO & NO $_{\mathbf{x}}$ & COD & Solid Waste \\
\hline I & 48,65 & 91,21 & 17,36 & 49,77 & 10,23 \\
\hline II & 0,16 & 0,03 & 0,36 & 0,00 & 0,00 \\
\hline III & 21,61 & 3,11 & 6,36 & 50,23 & 11,46 \\
\hline IV & 0,35 & 0,53 & 0,36 & 0,00 & 0,00 \\
\hline V & 4,52 & 0,74 & 14,62 & 0,00 & 0,00 \\
\hline VI & 0,44 & 0,65 & 0,46 & 0,00 & 0,00 \\
\hline VII & 24,19 & 3,59 & 60,31 & 0,00 & 0,00 \\
\hline VIII & 0,02 & 0,13 & 0,07 & 0,00 & 0,00 \\
\hline IX & 0,05 & 0,01 & 0,09 & 0,00 & 78,30 \\
\hline X & 0,00 & 0,00 & 0,00 & 0,00 & 0,00 \\
\hline XI & 0,00 & 0,00 & 0,01 & 0,00 & 0,00 \\
\hline
\end{tabular}


For the completeness of the analysis, some of the results are presented by each life cycle stage in Tables 4, 5 and 6. More precisely, the energy consumption (total fuel plus feedstock), the atmospheric emissions of carbon monoxide $(\mathrm{CO})$, and nitrogen oxides $\left(\mathrm{NO}_{\mathrm{x}}\right)$, the $\mathrm{COD}$ of the waterborne waste and the solid waste of three of the examined containers $(250 \mathrm{ml}$ glass bottle, $330 \mathrm{ml}$ aluminium can 202-type, and $500 \mathrm{ml}$ PET bottle) are analyzed in these Tables. According to the results of this analysis, it is easy to rank the relative contribution of each life cycle stage to the total environmental impacts and subsequently to evaluate opportunities to reduce them. However, an Improvement Assessment (in which options for reducing these impacts could be identified and evaluated) is more complicated as it needs ranking and selection of the options available, based on their effectiveness and other similar factors. It must also be noted that, since the purpose of this example is to show how LCA allows the identification of which stage in the life cycle cause the main environmental impacts (and not this identification itself), the analysis is limited in some of the LCI results. Furthermore, a relevant analysis for all of the calculated inputs and outputs of the Inventory phase, and for every container that is examined in this work, would require much more space for presentation and commentary while it would be out of its scope.

\section{CONCLUDING REMARKS}

There is a growing awareness of the need to take action against pollution and resource depletion, although how this could be done is not so obvious. Environmental problems have changed in the past decades to become more global, diffuse, delayed and complex. In this situation, a system perspective and a comprehensive view are necessary. There are different tools that can be used to achieve environmental improvements, one of which is life cycle assessment. LCA is a method for assessment of the environmental impacts of products, processes or services from raw materials to waste. The most important application of LCA are the analysis of the contribution of the substances to the overall environmental load, usually with the aim to prioritise improvements on products and processes, and the comparison between products for internal or external communications.
Both of these two applications are the main issue of the case study presented here. However, while the first of them (that is analysis of the overall environmental load) is being achieved through this LCI (as the results of it are a detailed list of emissions and raw materials), the second application (that is comparison between products) is not very easy to be fully achieved through Inventory Analysis and it is required to be completed by Impact Assessment. The problem is that the results presented in Tables 1-3 are complex and cannot lead to a clear-cut answer about which container has the lowest environmental impact. Apart from the apparent remark that the size of the containers significantly affects the results, which means that the bigger cans and bottles have better environmental performance than the smaller ones, the comparative appraisal and absolute judgment of them presents a lot of difficulties. The main problem of this appraisal is that LCA studies, almost always, result in numerous environmental effects expressed by many different units. Consequently, the "less is best" approach can be used only to identify, for each container, where the amount of a single pollutant that is released or the amount of a single resource that is consumed is higher or lower referring to the corresponding amount of the other containers or to a standard value and, therefore, if this amount could be possibly reduced. If a deeper analysis is desired in order to better understand and evaluate the magnitude and the significance of each result of the inventory phase, then the application of a life cycle impact assessment methodology is required, and especially the classification and characterization elements of it. However, even without the application of an impact assessment procedure (which makes LCI results very difficult to interpret), the benefit is that the result of the inventory phase is very detailed, and it is not affected by the uncertainties introduced in impact assessment. Moreover, according to the results presented in Tables 4, 5 and 6 , LCI can also be used to evaluate the contribution of individual steps or processes of the life cycle to the total environmental impacts, which could help identify possible areas of improvements and interventions.

From all the above it is obvious that, in spite of the drawbacks of the methodology (mainly the collection and quality of data, defining system 
boundaries, difficulties in assessment and interpretation of results, and the cost of the technique), LCA offers opportunities for assisting companies and policy makers in environmental management, as it provides indicators (like greenhouse gas emissions, climate change, resource depletion etc) of the sustainability of industrial systems. In this context, companies could increase LCA application through a process that starts with pilot projects, followed by establishment of internal knowledge and leading to a more systematic and prospective way of application. Moreover, LCA could be more deeply included in decision-making processes of a company through further integration of it into environmental management schemes. This process may generate more environmental benefits in the long run.

\section{ACKNOWLEDGEMENTS}

I would like to thank the anonymous referee for his critical remarks.

\section{REFERENCES}

Andersson, K., Eide, M.H., Lundqvist, U. and Mattsson, B. (1998), The feasibility of including sustainability in LCA for product development, Journal of Cleaner Production, 6, 289-298.

Assies, J.A. (1992), State of art, In: Report of Worksop on Life-Cycle Assessment organised by SETAC-Europe, December 2-3, 1991, Leiden, The Netherlands, pp. 1-20.

Barton. J.R., Dalley, D. and Patel, V.S. (1996), Life cycle assessment for waste management, Waste Management, 16, 35-50.

Bontoux, L. and Papameletiou, D. (1998), About the complexity of LCA applications in the field of waste management, In: Proceedings of Seminar on Life Cycle Analysis organised by Aristotle Univ. of Thessaloniki, December, 16, 1997, Thessaloniki, Greece, p.p. 97-101.

Bouman, M., Heijungs, R., Van der Voet, E., Van den Bergh J.C.J.M. and Huppes, G. (2000), Material flows and economic models: An analytical comparison of SFA, LCA and partial equilibrium models, Ecological Economics, 32, 195-216.

Dante, R.C., Guereca, L.P., Neri, L., Escamilla, J.L., Aquino, L. and Celis, J. (2001), Life cycle analysis of hydrogen fuel: A methodology for strategic approach of decision making, International Journal of Hydrogen Energy, 27, 131-133.

Ekvall, T. and Finnveden, G. (2001), Allocation in ISO 14041 - A critical review, Journal of Cleaner Production, 9, 197-208.

Ekvall, T. (2000), A market-based approach to allocation at open-loop recycling, Resources, Conservation and Recycling, 29, 91-109.

Forsberg, G. (2000), Biomass energy transport. Analysis of bioenergy transport chains using life cycle inventory method, Biomass and Bioenergy, 19, 17-30.

Frankl, P. and Rubik, F. (2000), Life cycle assessment in industry and business: Adoption patterns, applications and implications, Springer, Heidelberg.

Georgakellos, D. (1999), Life cycle analysis: A systematic tool in environmental management, Spoudai, 49, 126158.

Georgakellos, D. (1998), Comparative appraisal of the environmental effects of table water bottles on the Greek market using life cycle analysis, Technika Chronika Scientific Journal of T.C.G. - Section IV, 18, 35-47.

Goedkoop, M. and Oele, M. (2001), Introduction into LCA methodology and practice with SimaPro 5, PRe Consultants, Amersfoort.

Graedel, T.E. and Allenby B.R. (1995), Industrial Ecology, Prentice Hall / AT\&T, New Jersey.

Henn, C.L. and Fava, J.A. (1994), Life cycle analysis and resource management, In: Environmental Strategies Handbook, Kolluru, R.V. (ed.), McGraw-Hill, New York.

Herrchen, M., Keller, D., Lepper, P., Mangelsdorf, I. and Wahnschaffe, U. (1997), ELA 1,0 - A framework for life-cycle impact assessment developed by Fraunhofer - Gesellschaft. Part A: The conceptual framework, Chemosphere, 35, 2589-2601.

Hunkeler, D., Rebitzer, G., Jensen, A.A. and Margni, M. (2001), Life cycle management: Bridging the gap between science and application, International Journal of LCA, 6, 384 - 390.

Huybrechts, D., Berloznik, R., Wouters, G., Marion, J.-Y., Valenduc, G. and Vendarim, P. (1996), The role of ecobalances in environmental decision-making, Journal of Cleaner Production, 4, 111-119. 
Kasai, J. (1999), Life cycle assessment, evaluation method for sustainable development, JSAE Review, 20, 387-393. Kuta, C.C., Koch, D.G., Hilderbrandt, C.C. and Janzen, D.C. (1995), Improvement of products and packaging through the use of life cycle analysis, Resources, Conservation and Recycling, 14, 185-198.

Nieuwlaar, E., Alsema, E. and Van Engelenburg, B. (1996), Using life-cycle assessments for the environmental evaluation of greenhouse gas mitigation options, Energy Conversion Management, 37, 831-836.

Rubik, F. and Baumgartner, T. (1992), Technological innovations in the plastics industry and its influence on the environmental problems of plastic waste - Evaluation of eco-balances, Commission of the European Communities, Luxembourg.

Scholl, G.U. and Nisius, S. (1998), The environmental benefits to German companies through application of LCA, Journal of Cleaner Production, 6, 247-252.

Udo de Haes, H.A., Bensahel, J.-F., Clift, R., Fussler, C.R., Griesshammer, R. and Jensen, A.A. (1997), Guidelines for the application of life cycle assessment in the EU Eco-Label awarded scheme, Commission of the European Communities, Luxembourg.

Vigon, B.W. and Jensen, A.A. (1995), Life cycle assessment: data quality and databases practitioner survey, Journal of Cleaner Production, 3, 135-141.

Vigon, B.W., Tolle, D.A., Cornaby, B.W., Latham, H.C., Harrison, C.L., Boguski, T.L., Hunt, R.G. and Sellers, J.R. (1993), Life cycle assessment: Inventory guidelines and principles, U.S. Environmental Protection Agency, Washington, DC. 